\title{
VISUAL RECOGNITION OF GRAPHIC VARIANTS OF AMHARIC LETTERS: PSYCHOLINGUISTIC EXPERIMENTS
}

\author{
FEDA NEGESSE AND DERIB ADO
}

\section{ABSTRACT}

One of the problems of Amharic orthography is a lack of consistency where the four Amharic sounds (/h/, / /, /s/ and /s'/) are mapped onto more than a single letter. The objective of these psychological experiments was to investigate the visual recognition of the graphic variants of the letters, both in isolation and within words. The experiments involved computation of the frequency counts of the letters in the Ten Ten Corpus for Amharic and the result revealed that there is a clear pattern of preference for the letters: the letters representing $/ \mathrm{h} /$ had the pattern $\langle\boldsymbol{U}\rangle\langle\mathrm{h}\rangle$ $\langle\overrightarrow{\langle}\rangle$, the letters representing $/ \mathrm{l} /$ had the pattern $\langle h\rangle\langle 0\rangle$, the letters representing /s/ had the pattern $\left\langle\dot{\phi}>\langle\boldsymbol{\omega}\rangle\right.$, and the letters representing $/ \mathrm{s}^{\prime} /$ had the pattern $\langle\boldsymbol{\gamma}\rangle\langle\boldsymbol{\theta}\rangle$ in descending order of frequency. Similarly, the experiments indicated that frequency counts are significantly related to visual recognition of a letter, with the more frequent letters recognized faster with fewer errors. It was also observed that the target letters were recognized with a shorter reaction time when they were paired with themselves, but the recognition time was longer when they occurred with their graphic variants. Moreover, significantly higher percentage of errors were made when the target letters were matched with their graphic variants or their distractors in the alphabet recognition task. Similar patterns were also observed in the lexical decision task when the target letters were presented in words and pseudo-words. More rigorous psycholinguistic experiments, which will involve a large number of participants, are recommended to validate the results of the current experiments.

\section{[1] INTRODUCTION}

There is a large body of empirical evidence which shows that letters constitute the smallest perceptual units in visual recognition of words (Fiset et al. 2008). For instance, Pelli et al. (2003) reported that a word cannot be read if its letters are not separately decoded. Employing a masking technique, they observed that the stimulus energy for the recognition of a word is directly related to the number of letters. Similarly, Martelli, Majaj \& Pelli (2005) found that word 
recognition starts with the identification of individual letters and this finding is inconsistent with the Gestalt view that words are holistically recognized (Pelli, Farell \& Moore 2003). In Hong Kong, where early reading focuses on identification of logograms or characters, children found it difficult to read English words by associating graphic symbols with their corresponding sounds, but when taught phonemic awareness, they showed a significant improvement in their word recognition skills (McBride-Chang \& Treiman 2003). A study conducted by Share and Gur (1999) also indicated that alphabetic and phonological skills play a key role in the improvement of word recognition ability of children in early reading. The studies reviewed above point to the importance of letters in word recognition.

\section{[2] VISUAL LETTER RECOGNITION}

Two contradictory views exist to explain the processes of word recognition, which also cast light on the visual recognition of letters. The orthographic depth hypothesis states that graphic symbols which constitute a word are changed into sounds and then into a phonological representation of the word before semantic recoding (Chitiri \& Willows 1994, Cho \& Chen 1999). However, in logographic languages, word recognition depends on the visual decoding of a word as a whole unit directly into its semantic representation without a phonological interface (Huang \& Hanley 1994, Ju \& Jackson 1995). On the other hand, according to the universal phonological principle, word recognition involves an automatic activation of phonological information, irrespective of orthography (Lesch \& Pollatsek 1993, Lukatela \& Turvey 1994). Common to both views is that word recognition begins with the decoding of letters or logographs, which are composed of physical features such as vertical, diagonal or horizontal lines, closed or open curves, and intersection (Gibson 1969). These features constitute basic structures or global shapes of letters, and it is believed that identifying these global features is enough for the visual system to recognise letters (James et al. 2005). Nonetheless, studies (Sanocki 1992, Sanocki \& Dyson 2012) indicate that response time is shorter when strings are presented in the same font and that lowercase letters are easier to recognize, which means readers also decode information about shapes or fonts of letters.

There has been a lot of evidence from neurological studies which identified neural substrates related to processes, which are responsible for the decoding of features of letters. For example, Hubel and Wiesel (1968) noted that there were cells that appeared to be especially sensitive to visual stimuli, which mapped onto such things as vertical lines, horizontal lines, angles, and even motion. The objective of this investigation was to provide the neurological evi- 
dence that converged with the notion that pattern recognition ultimately depends upon primitive feature analytic processes. Using positron emission tomography, Petersen et al. (1990) found a significant flow of blood variations in specific areas of the cortex, corresponding to feature-like detection systems in humans. In addition, an event-related potential study indicated that while processing letter shapes, subjects can have access to top-down information found in visual word form representations (Martin et al. 2006). The visual system does not scan letters in a sequence, rather it extracts features of letters simultaneously in a word (Rayner \& Johnson 2005, Adelman, Marquis \& Sabatos-DeVito 2010). Letter-by-letter reading is not the behaviour of normal readers and is considered a neural deficit associated with a reader's inability to fixate a chunk of letters (Pugh et al. 2001, Rayner \& Johnson 2005). Taken together, the studies reviewed above suggest that letter recognition in words involves parallel processes where letter features can be directly decoded from the incoming stimuli or /and where the information about letter identity can be retrieved from memory.

\section{[3] FACTORS AFFECTING VisUAL LETTER RECOGNITION}

Previous studies indicate that spatial resolution, contrast, letter case, disposition of the human visual system, and the type of cognitive activity needed are factors which influence letter identification tasks: Pelli, Palomers \& Majaj (2004), Grainger, Tydgat \& Issele (2010), Demirel, Anderson, Dakin \& Thibos (2012), Kwon \& Legge (2013). One such study was conducted by Arguin et al. (2008) who reported that when compared with other features (curves open right, curves open bottom, verticals, slants tilted left, curves open top, intersections, slants tilted right and horizontals), terminations provide more vital information for differentiating letters. They argue that the weight given to letter terminations can be influenced by our visual system, which tends to focus on such features. The visual system seems to draw more on one feature when the other one fails to provide all the required information. When the spatial resolution is poor, the system needs higher contrast to identify letters (Kwon \& Legge 2013). On the other hand, an experiment conducted on English uppercase letters shows that removal of vertices of letters impedes identification more than that of midsegments, as filling in the missing information may be difficult when vertices are deleted (Lanthier et al. 2009). The studies are contradictory; rather they suggest that the letter features compensate one another and the visual system utilizes available information to identify letters and some features carry more weight than others.

Several studies show that letter frequency seems to influence timed tasks 
such as letter matching, naming and classification tasks, but it does not appear to affect accuracy in identification tasks (Appelman \& Mayzner 1981). Behavioural studies also documented that contexts are one of the key factors which affect recognition of letters. It is also reported that letters are recognised faster in words than in isolation and they are better identified when put in words than in nonwords, or in pronounceable rather than unpronounceable nonwords (Coch \& Mitra 2010). In addition, Rey \& Schiller (2005) indicated that the recognition of a letter takes longer when it is embedded in a complex grapheme (e.g. ' $A$ ' in BREAD) than when embedded in a simple grapheme (e.g. ' $A$ ' in PLACE). It is speculated that the letter ' $A$ ' in the word, BREAD competes with three vowel graphemes whereas it competes with only two vowel graphemes in the word, PLACE, taking relatively shorter time. Probably, it seems more difficult to recognise a letter in a complex grapheme than in a simple grapheme (Rey et al. 2000). On the contrary, a word context helps readers to predict the remaining letter(s) based particularly on the first letters, a phenomenon termed as phonemic restoration (Kashino 2006). For instance, an English reader can predict the last letter of the word 'fable' as there is only one possible candidate. Related to the tendency of readers to attend to some letters of a word is the observation that they fixate first and longer on the first letters than on other letters in the word, which suggests that readers are perceptually biased towards letters in an initial position, due to their relative importance (Evans et al. 2009).

\section{[3] FEATURES OF AMHARIC ORTHOgRAPHY}

Orthographies are ingenious human creations, which have evolved over centuries to represent various linguistic elements of the spoken language such as phoneme, syllable, and morphophonemes (Frost 2005). One such invention is Amharic orthography or fidel, in which each character has seven orders, representing syllabic combinations of consonants and vowels. The Amharic writing system is dominantly syllabary (Leslau 2000) but some writers (Moges 2010, Leslau 2000) argue that it is alphasyllabic as the sixth order of fidel can occur with or without the central high vowel in different positions in words ( e.g.

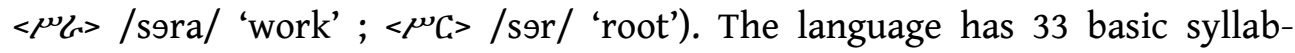
ographs and $231(33 \times 7)$ variants composed of the basic syllabographs and the seven vowels (TABLE 1). 


\begin{tabular}{|c|c|c|c|c|c|c|}
\hline $1^{\text {st }}$ & $2^{\text {nd }}$ & $3^{\text {rd }}$ & $4^{\text {th }}$ & $5^{\text {th }}$ & $6^{\text {th }}$ & $7^{\text {th }}$ \\
\hline$v$ & $u$ & $\psi$ & 4 & 4 & $v$ & $u^{P}$ \\
\hline$\lambda$ & 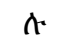 & $\psi$ & $\lambda$ & 4 & $\Delta$ & $\lambda^{\circ}$ \\
\hline$h$ & h & h. & $h$ & か & d̆ & $\boldsymbol{h}$ \\
\hline$\sigma D$ & $\boldsymbol{\sigma D}$ & ${ }^{\alpha} q$. & $\sigma_{9}$ & $\sigma_{\mathbf{g}}$ & qd & $q \mathrm{D}$ \\
\hline$w$ & $w$ & 내. & 버 & 낭 & $\mu$ & $\psi$ \\
\hline L. & c. & 6 & 6 & 6 & $C$ & $\mathcal{C}^{\mathcal{L}}$ \\
\hline$\hat{n}$ & $\dot{\phi}$ & ḋ. & $\dot{\lambda}$ & ḋ & h̀ & $\hat{d}$ \\
\hline$\pi$ & 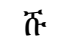 & 'T & $\pi$ & '九 & $\pi$ & $\pi$ \\
\hline$\phi$ & $\phi$ & $\Phi$ & 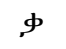 & $\mathbf{B}$ & $\dot{\phi}$ & $\phi$ \\
\hline n & 0. & $\mathrm{n}$ & $\eta$ & $\mathrm{n}$ & $n$ & n \\
\hline+ & 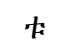 & $\mathrm{t}$ & 小 & $b$ & 市 & p \\
\hline 平 & 定 & 玉 & F & 㝒 & 第 & 兼 \\
\hline " & 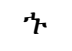 & "ל. & 3 & 'b & 7 & iq \\
\hline 3 & 4 & ל. & $G$ & b & 3 & q \\
\hline ' & 家 & 's. & ' ' & $\mathrm{c}$ & 3 & 审 \\
\hline ' h & 多 & ' & 公 & ל & $\hbar$ & 'h \\
\hline$h$ & $h$ & $\mathrm{~h}$ & $\eta$ & $\mathrm{h}$ & $\mathrm{h}$ & $h$ \\
\hline 't' & $\pi$ & 'ָ & '万 & 't & 't & Th \\
\hline $\boldsymbol{\omega}$ & $\omega$. & $\Phi$ & $\phi$ & $\mathbf{Q}$ & $\omega$ & $\varphi$ \\
\hline 0 & 0. & $q_{2}$ & 9 & $a_{b}$ & $\delta$ & p \\
\hline H & $H$ & $\mathrm{H}$. & H & H & $H$ & $H$ \\
\hline $\mathrm{Tr}$ & If & $\mathfrak{T C}$ & 'भ & 76 & 'rr & $\eta r$ \\
\hline$\rho$ & $\rho$ & $P_{2}$ & $\rho$ & $\rho_{0}$ & $e$ & p. \\
\hline$P$ & 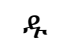 & $q$ & 9 & $e_{0}$ & : & $g$ \\
\hline $\bar{P}$ & 宗 & 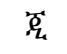 & $\bar{R}$ & $\mathscr{P}_{0}$ & 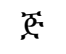 & 's \\
\hline 7 & $\gamma$ & 2 & ? & 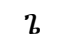 & ๆ & 7 \\
\hline$a$ & $a^{2}$ & $\mathrm{a}$. & $\eta$ & $\mathrm{a} b$ & $T$ & a \\
\hline њ & ↔в & $6 \mathrm{~B}$ & ๘ & க口 & $\widetilde{a b}$ & 6 \\
\hline k & 名 & $\dot{z}$ & k & $\dot{\phi}$ & ki & $\dot{2}$ \\
\hline 2 & 8 & 2. & 2 & 8 & 8 & 8 \\
\hline$\theta$ & $\theta$ & q. & 9 & $q$ & $\dot{\theta}$ & 8 \\
\hline b. & 4 & 6 & 4. & $b_{0}$ & F: & G \\
\hline$T$ & $\mathrm{~F}$ & $\mathrm{~T}$ & $T$ & $\mathrm{~T}$ & $T$ & $T$ \\
\hline
\end{tabular}

TABLE 1: List of Amharic basic letters (fidel) with their corresponding seven orders, where the shapes are constrained by the vowels they represent. The letters for the borrowed and lately included $<\vec{n}>$ and the symbols for labialized consonants are not on the list. 
The first order appears to be the basic form, while the rest are derived when the structure of the basic letter is modified in some regular ways. The structural change in the first order, which is a combination of the consonant and the vowel $/ 3 /$, is intended to represent the remaining six vowel letters $(/ a /, / e /$, $/ \mathrm{u} /, / \mathrm{o} /, / \mathrm{i} /, / 3 /, / \mathrm{g} / \mathrm{l}$. The change involves modifying the structure of the basic character by adding a straight line, or shortening or lengthening one of its main legs. It also includes the addition of small extensions, such as strokes, loops to the right, left, top or bottom of the basic character, which helps to derive the other vowels (TABLE 1). Amharic letters have similar shapes, which may make the task of recognition hard for machine and humans (Bloor 1995). These features are particularly interesting in research on visual letter recognition, because in alphasyllabic languages such as Amharic small changes in the basic physical features may affect orthographic identities of letters and phonological representations of their vocalic components.

Unlike English and other languages which employ Latin-based writing systems, Amharic does not have lower and upper cases. However, Amharic letters can be written in different fonts, as with any other language, but the fonts may not be as important as the shapes of the letters because the shapes constitute structures that determine the identity of the consonant and the corresponding vowel. Skilled readers of the language know that they have to pay close attention to the physical features of the characters, since they could easily miss the vowel signs which are structural parts of the consonants found in different orders (TABLE 1).

The other distinguishing feature of Amharic orthography is orthographic inconsistency, where some phonemes are represented by more than one character or letter (Ziegler, Ferrand \& Montant 2004, Ranbom \& Connine 2011). This overrepresentation of some phonemes is attributed to the historical fact that the Amharic orthography has evolved from Ge'ez, in which the redundant letters stand for distinctive sounds but latterly merged to represent a single phoneme and were inherited into the Amharic orthography (Daniels, 1999). From a linguistic point of view, we wondered how frequently the redundant letters are used in representing their corresponding phonemes. We also ask if users of the language recognise the redundant letters and their graphic variants differently in terms of reaction time and response accuracy. In addition, we wondered how much gender and frequency of use interact with the visual recognition of the redundant letters. Finally, we raise the issue of context, to know if the redundant letters are recognised faster in isolation than in words. To our knowledge,

[1] The phonetic and phonemic representations of some Amharic vowels are debatable or at least not clear; see (Derib 2011) for a detailed explanation. 
no study has been carried out to answer the above questions and thus our intention is to conduct psycholinguistic experiments to find answers for the questions.

\section{[4] METHOD}

We conducted two related experiments and the first experiment was intended to assess the recognition of the redundant letters in isolation, while the second experiment was aimed at examining the recognition of the letters in words. The methods employed in both psycholinguistic experiments were similar and thus no separate descriptions of method was needed for each experiment.

\section{[4.1] Participants}

Thirty students who were enrolled in the summer and evening programs at the College of Education and Behavioural Sciences, and the College of Humanities, Language Studies, Journalism and Communication participated in the experiments. All of them were native speakers of Amharic and they reported no medical histories such visual, motoric and intellectual impairments which could interfere with their involvement in the experiments. The number of female and male participants is equal and their average age was 32, with the standard deviation of 1.5. The participants took part in the experiments on a voluntary basis and were told that they could withdraw at any time in the course of the experiments.

\section{[4.2] Stimuli}

There were two sets of stimuli for the alphabetic and lexical decision task experiments. In the alphabetic decision task, the target letters were paired up with themselves (e.g., $<h h>$ both representing / $2 a /$ ), with their graphic variants (e.g. $<h 0>$ both representing / $/ \mathrm{a} /$ ), and with distractors (e.g. $<\lambda \lambda>$ the first one representing $/ \mathrm{la}$ /and the second one representing $/ \mathrm{l} /$ /) representing different phonemes (FIGURE 1). Only letters which have the same vowels were paired up, which means that letters in different fidel orders were not combined to make a pair. When the target letters were paired with the distractors, similarities in shape and size were considered. 

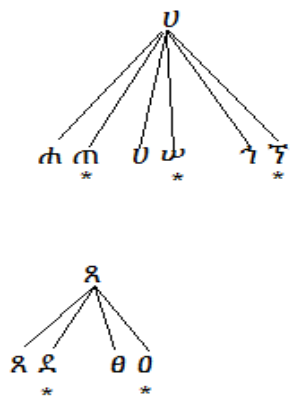
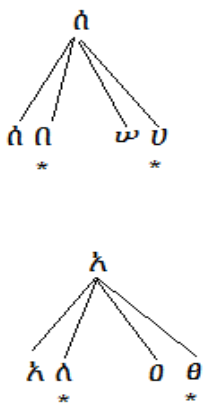

FIGURE 1: A schematic pairing of the letter stimuli for the experiments: the lines linked the target letters with themselves, with their graphic variants and with other letters which served as distractors. The asterisk marks the distractors.

The total number of stimuli in the alphabetic decision task (4 pairing $x 3$ graphic variants $\mathrm{x} 7$ orders +4 pairings of two graphic variants $\mathrm{x} 7$ orders $\mathrm{x} 3$ syllabographic kinds) is 164 . The stimuli were randomised and no stimulus was presented more than once. The frequency counts of the stimuli were calculated per million words in the corpus being developed by the Habit Project ${ }^{2}$ (FIGURE 2).

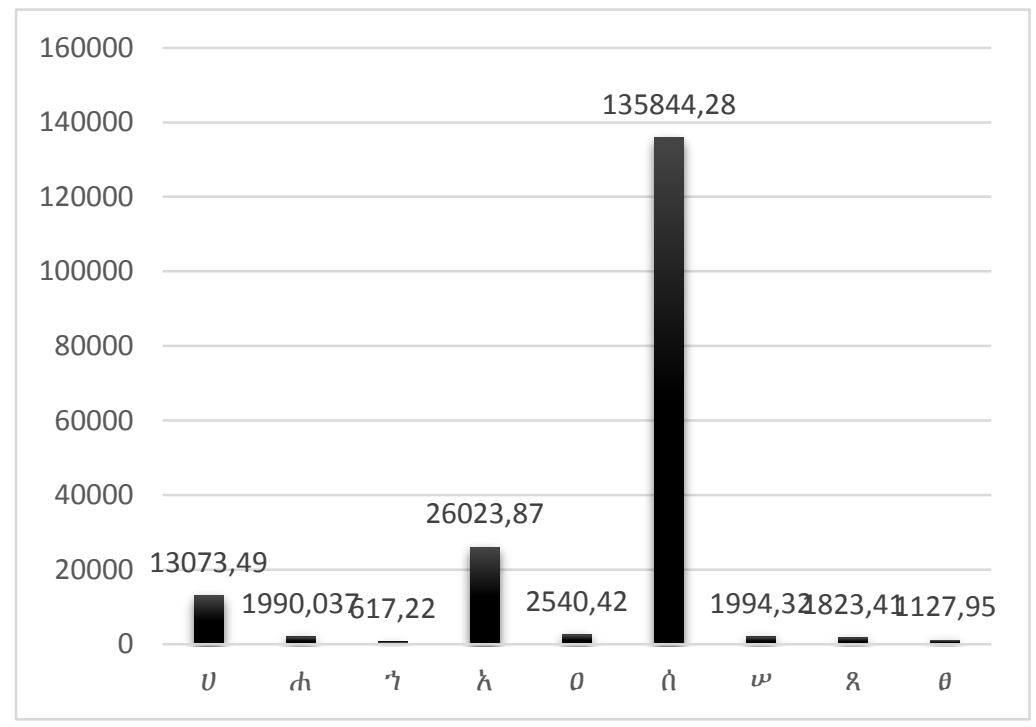

FIGURE 2: Frequency counts of the letters computed per million words.

The intention in computing the frequency counts of the graphic elements was to see if frequency of occurrence in the text corpus being built by Natural Lan-

[2] The Habit project is a collaborative project between Masaryk University of Czech and the Norwegian University of Science and Technology, and University of Oslo. We are grateful to the Habit project for allowing us access to the Amharic Ten Ten text corpus. 
guage Processing Centre of Masaryk University with the cooperation of Oslo University and Norwegian University of Science and Technology would affect a visual recognition of the graphic characters. It is possible to see that the three letters $\langle\hat{l}\rangle,\langle\hat{h}\rangle$ and $\langle\vec{b}\rangle$ are much more frequent than their graphic variants. The difference in frequency of occurrence between $\langle q\rangle$ and $\langle\theta\rangle$ is not very large, but $<\imath>$ is more frequent than its variant.

Most Amharic writers use the 'preferred' letter for those sounds which have more than one representation. For instance, in the Amharic Ten Ten corpus,

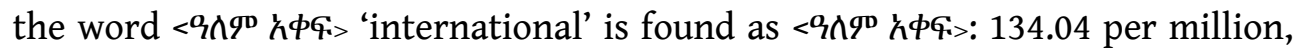

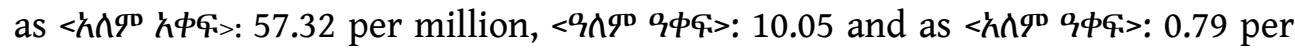
million. The historically appropriate form (according to Ge'ez writing tradition) for the term 'king' is $\langle 37 \mu\rangle$, but Amharic writers also use the form $\langle 37 \lambda\rangle$. In the Amharic Ten Ten corpus, the preferred form $<37 \mu>$ appears 97.5 per million and the other form $<37 \lambda>$ appears 56.33 per million, demonstrating that a significant portion of writers do not care about the etymology of words. It has to be noted that this count is found in a religious text dominated corpus, which is more conservative in selection of letters whenever there is more than one possibility. If one tries to include all other genres, the numbers will definitely be in favour of the free will use of the letters. It is probable that the letters may be losing their sociolinguistic value to instead just exist as graphic variants representing the same phoneme.

\section{[4.3] Apparatus}

All the experiments were run with DMDX (Forster and Forster, 2003). The stimuli were presented on a 17" HP LCD monitor with a refresh rate of $70 \mathrm{~Hz}$ and a resolution of 1280 by 1024 pixels, placed at a distance of about $60 \mathrm{~cm}$ from the participants. The monitor was controlled by a PC Core Duo (HP Precision 390). The stimuli were also presented in lowercase Courier New font 12, and appeared on the screen as black characters on a grey background.

\section{[4.4] Procedures}

The experiment was conducted in our Phonetics Laboratory with HP PCs connected to high resolution LCD monitors. Stimuli presentation and data recording were controlled by DMDX software (Forster and Forster, 2003). A trial began with a centred 500-ms fixation point (+) that was immediately replaced by the target word, which remained on the screen for a maximum of $1300 \mathrm{~ms}$ until a response was produced. For the alphabetic decision task, the participants were told to press the right shift key if the stimuli (a pair of letters) displayed on the screen represented the same phonemes and press the let shift key if the stimuli 
represented different phonemes. For the lexical decision task, they were told to press the right shift key if the stimulus (a string of letters) displayed on the screen was a real word in Amharic and press the let shift key if the stimulus was not a real word in Amharic. The participants were told to respond as quickly and accurately as possible, without making many errors. Before the experiments, the participants familiarised themselves with the procedure by doing a short lexical decision task.

\section{[5] Results}

\section{[5.1] Experiment 1}

This experiment is an alphabetic decision task intended to assess (in isolation) the visual recognition of the graphic variants of Amharic letters which stand for the four Amharic phonemes. The results of the experiment are presented based on two variables: gender and stimulus type.

\section{Reaction Time}

Gender is one of the variables that can affect reaction time to a graphic stimulus, and thus we wanted to know if there is a significant difference between female and male with respect to the reaction time in visual recognition of the graphic variants. As FIGURE 3 shows, the male participants ( $M=592.75 \mathrm{~ms}$ ) took significantly more time than the female participants $(575.87 \mathrm{~ms})$ did in deciding whether the Amharic letters in question were the same or different $[F(1,30)$ $=8.79, P=0.003]$. 


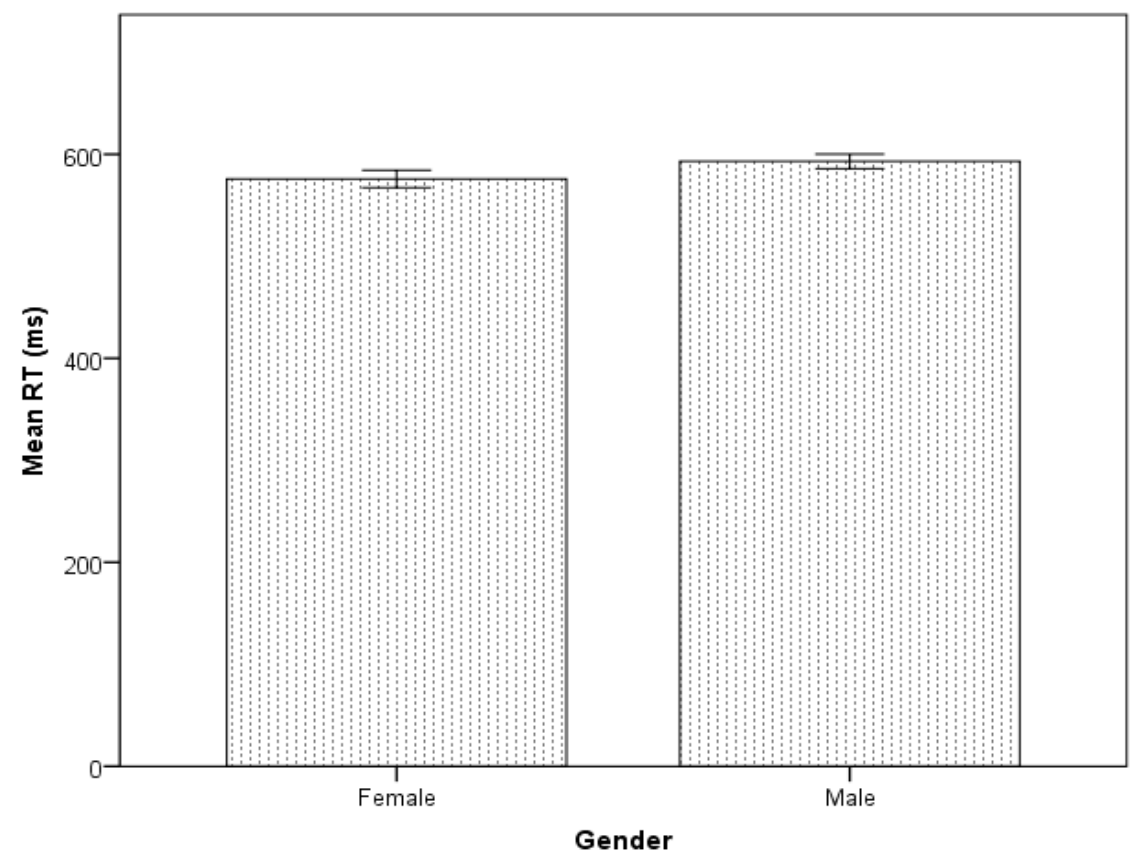

FIGURE 3: Reaction time of both genders in a same-different judgement task. The errorbars indicate $95 \%$ confidence intervals.

Because the recognition of letters is partly determined by their features, we expected that some target letters are recognised faster when they are presented with the same letters, than with their graphic variations. As explained earlier, we matched the target letter with itself (Self), its graphic variants (Allograph) and with a different letter (Distractor). We assumed that when a target letter is presented with itself, it would be easier to recognise than when it is presented with its graphic variant, or distractor, because of sameness of physical features and repetition priming. 


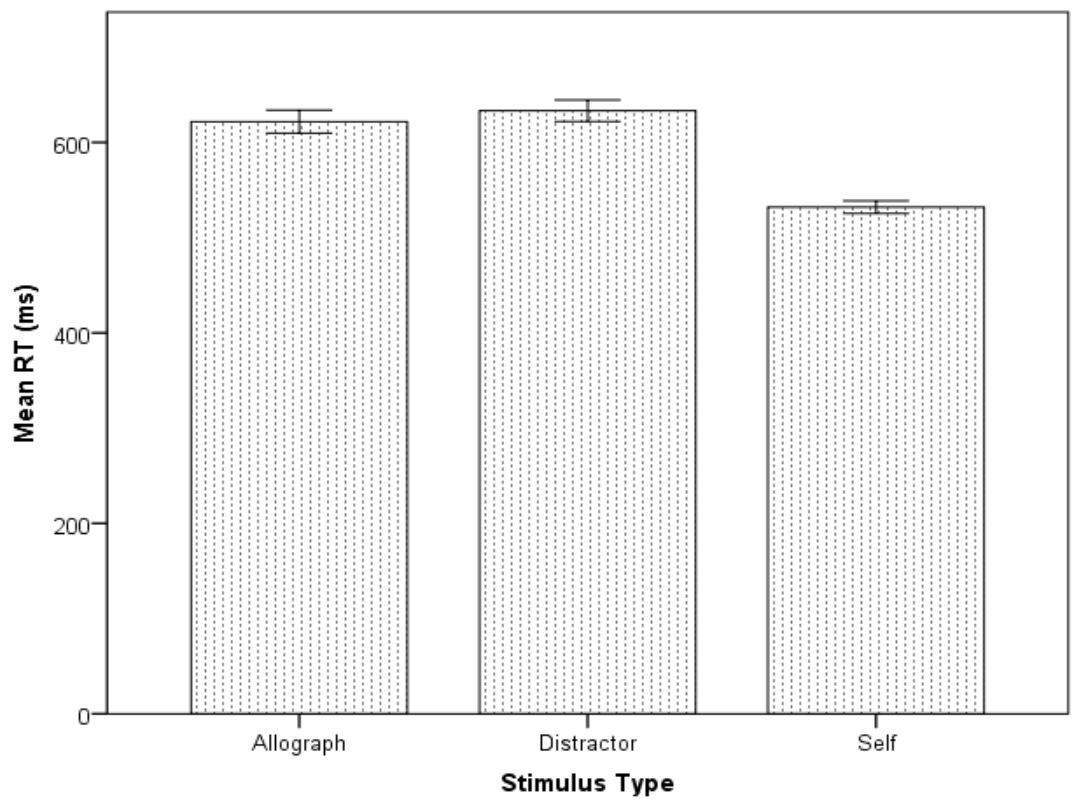

FIGURE 4: The reaction time of the redundant Amharic letters and the reaction time was measured in milliseconds. The errorbars indicate $95 \%$ confidence intervals.

It is interesting to see that the reaction times of the letters were different when they were presented with themselves $(532.04 \mathrm{~ms})$, their allographs $(621.84 \mathrm{~ms})$ and distractors $(621.38 \mathrm{~ms})$. Consistent with our expectation, the reaction time of letters was very short when they were matched with themselves, which shows that the participants could more easily recognise the letters. The allographs and the distractors tend to take an almost equal amount of time to be processed by the participants and this suggests that visual recognition of the letters requires a similar amount of processing time. The difference is significant when the means of their reaction times were compared with One-way $\operatorname{ANOVA}[F(2,30)=151.00, P=0.00]$.

\section{Accuracy}

As explained earlier, gender is one of the variables considered in the experiment to see it is linked to visual letter recognition. The experiment shows a clear gender difference in the percentage of correct recognition of the characters (FIGURE 5). The female participants had a significantly greater percentage of accurate responses $(77.2 \%)$ in recognising the letters in isolation $\left[x^{2}(1,30)=\right.$ $8.64, p=0.003$, which is indicative of the association of gender and visual letter recognition. 


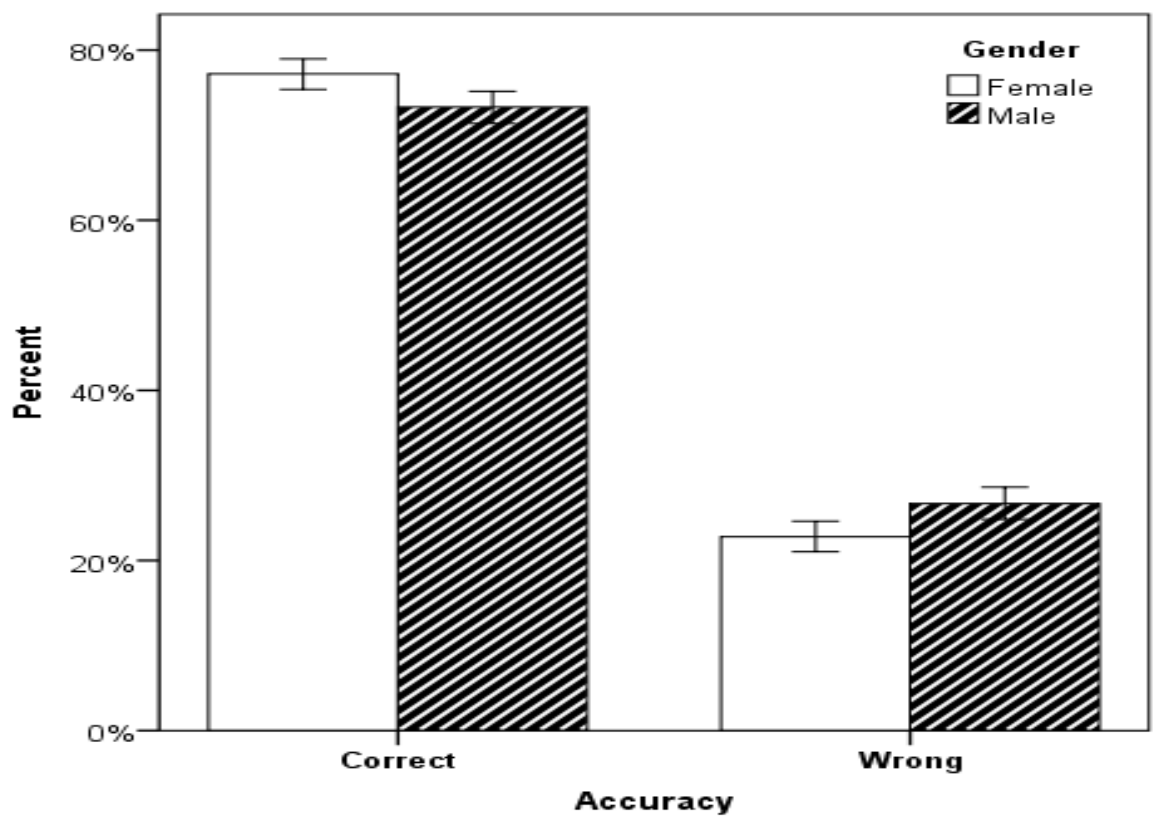

FIGURE 5: The percentages of recognition accuracy of letter by male and female participants. The errorbars indicate $95 \%$ confidence intervals.

Percentages of accurate recognition were computed for the target letters (i.e. the most or more frequent letters), allographs and distractors in order to determine if the target letters received more correct responses than their graphic variants, which are relatively less frequent. 


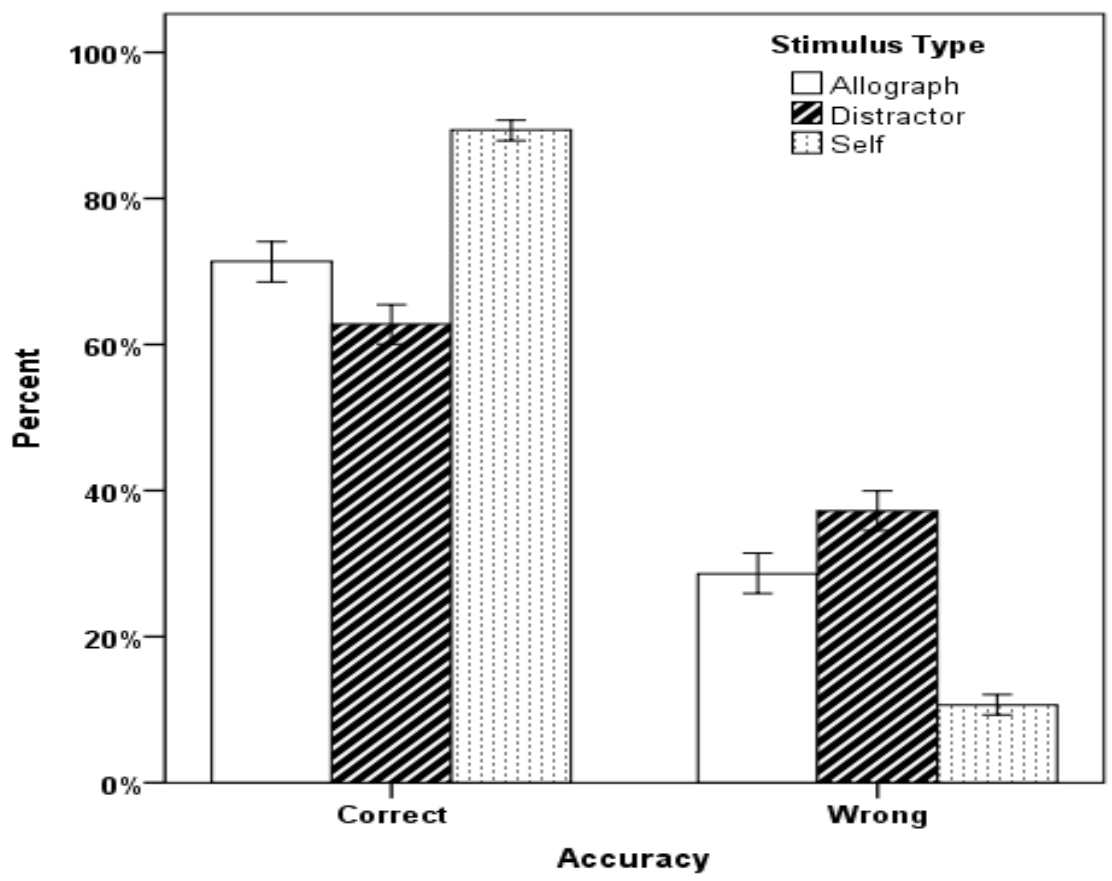

FIGURE 6: The percentages of recognition accuracy of letter by letter and stimulus types. The errorbars indicate $95 \%$ confidence intervals

FIGURE 6 shows that the target letters $(88.1 \%)$ had significantly higher percentage of correct responses than their allographs or the distractors $\left[X^{2}(2,30)=329\right.$, $P=0.00]$. It is also interesting to see that the distractors (60.7 \%) and the allographs $(69.6 \%)$ had a close percentage of accurate recognition, which may indicate that letter recognition requires processing their physical features. Alternatively, the participants might have decided if the letters in pairs were different or the same by matching their features, since matching letters with themselves and with their phonological representations may be easier due to repetition priming and phonological consistency.

\section{[5.2] Experiment 2}

The second experiment was concerned with the visual recognition of Amharic graphic variants in words, where the variables were gender and stimulus category. The variables were assessed in terms of reaction time and percentage of accurate recognition.

Reaction Time

Reaction time was examined based on such variables as gender and stimulus 
type to see if significant differences exist in the time participants took to recognise the graphic variants of Amharic letters. Both male $(M=590.74 \mathrm{~ms})$ and female $(M=586.26 \mathrm{~ms})$ participants recognised the letters in a similar amount of time, which suggests that gender difference is not significant in recognising letters in isolation $[F(1,30)=0.29, P=0.005]$. However, it is noted that the female participants took a significantly shorter time to recognise the letters in isolation, which indicates that gender may have not a significant effect on the recognition in graphic variants of the letters when the letters are presented in words.

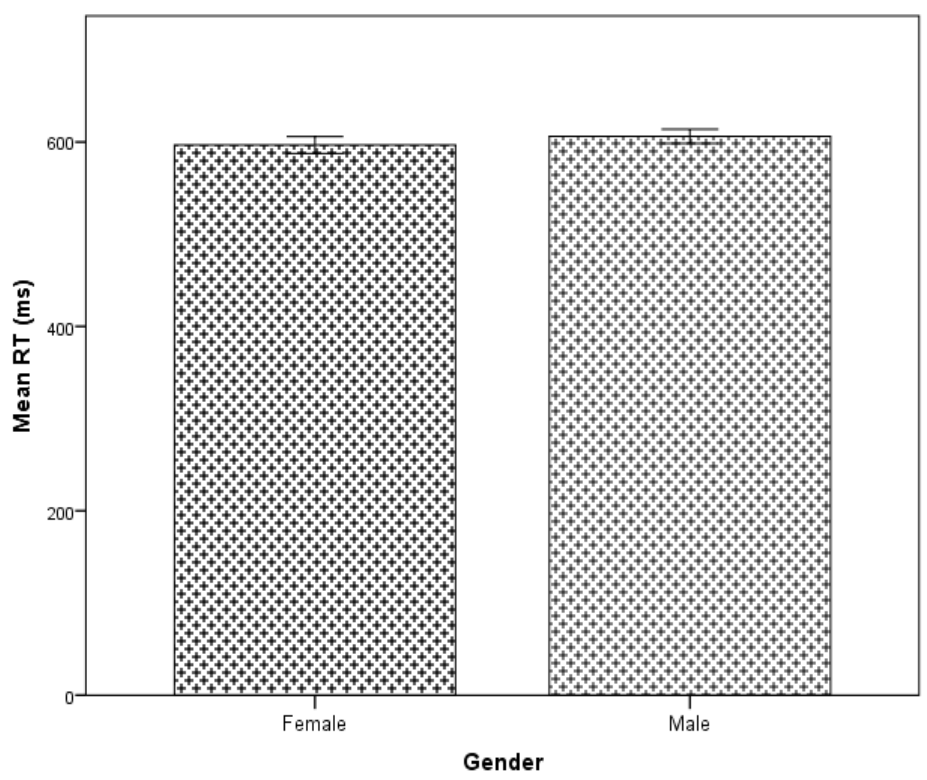

FIGURE 7: Reaction time of male and female participants in recognition of letters in word contexts. The errorbars indicate $95 \%$ confidence intervals.

Frequency of occurrence and stimulus type

We expected that some letters would be recognised faster than their graphic variants, depending on their frequency when the target letters were presented in words. The participants took a longer time to recognise the less frequent letters, which suggests that frequency of occurrences (which means frequency of use) affects recognition of letters in words, but the effect was not significant in this experiement $[F(1,30)=1.33, P=0.25]$. 

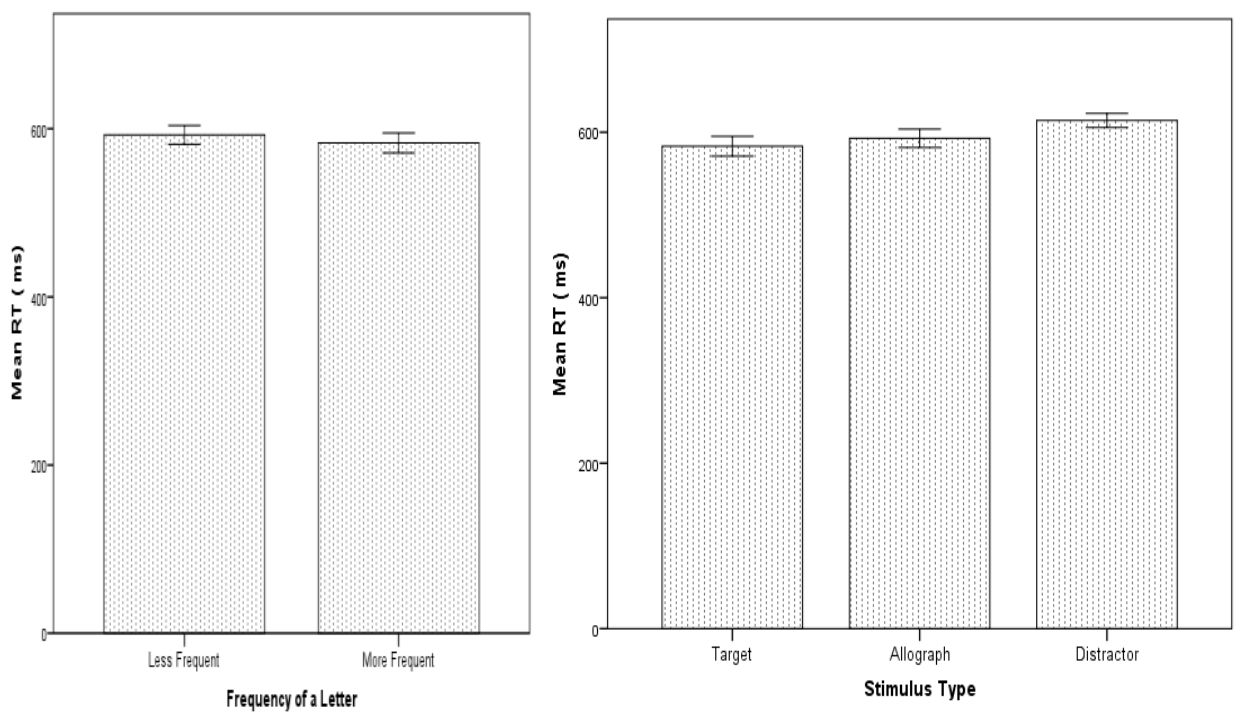

FIGURE 8: Mean reaction time of the participants computed based on letter frequency and stimulus type. The errorbars indicate $95 \%$ confidence intervals.

It is also possible to see that the targets $(583.12 \mathrm{~ms})$ (which are the more frequent letters) were recognised significantly faster than their allographs (592.70 $\mathrm{ms})$, and the allographs took a significantly shorter time than the distractors $\operatorname{did}(614.29 \mathrm{~ms}) \operatorname{did}[F(1,30)=9.79, P=0.00]$. We hypothesize that the targets are the graphemes representing the sounds, while the allographs are their graphic variants which are mapped into their graphemes.

\section{Accuracy}

FIGURE 9 reveals that gender is associated with the percentage of recognition accuracy of letters in words. The female participants had greater percentage of accuracy as compared to male participants and the difference is significant when the data were submitted to the Chi Square Test $\left[X^{2}(1,30)=35.02, P=0.00\right]$. It is not clear why gender difference is significantly associated with percentage of correct recognition of letters, regardless of whether letters are presented in isolation or words. 


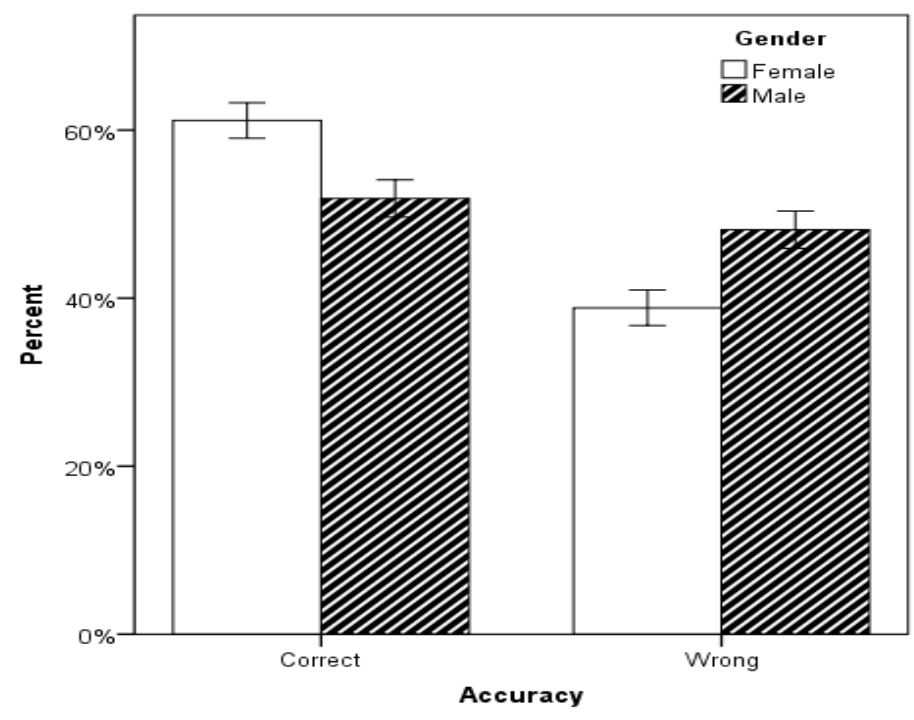

FIGURE 9: Percentages of correct and wrong answers for male and female participants. The errorbars indicate $95 \%$ confidence intervals.

With regard to incorrect recognition, it was observed that the male respondents tended to make more errors than their female counterparts did in the second experiment and the difference was significant, showing interaction of gender with percentage of visual letter recognition.

Frequency of occurrence and stimulus type

Letter frequency and stimulus type are expected to have a significant association with percentage of accurate recognition of letters in words. Consistent with the previous studies and our intuitive expectations, letters with greater frequency of occurrence had a significantly higher percentage of correct recognition $\left[X^{2}(1,30)=4.09, P=0.04\right]$ and this shows that frequency of occurrence has a marginally significant association with a letter recognition. 

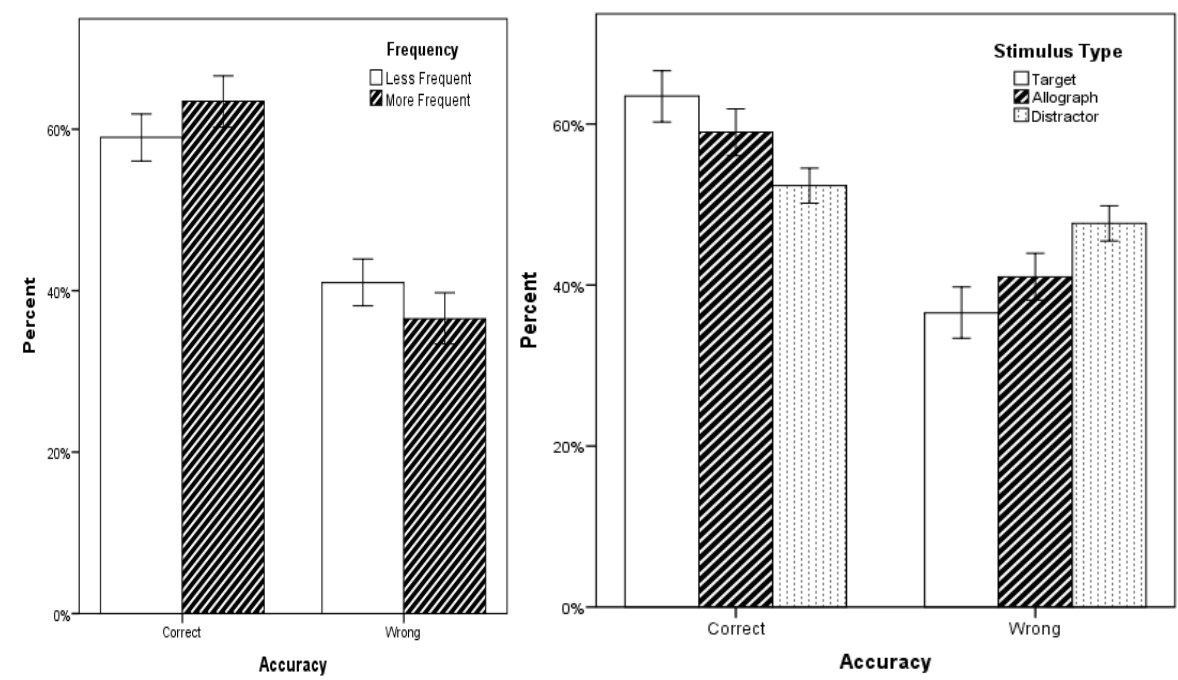

FIGURE 10: Percentages of correct and wrong responses computed for letter frequency and stimulus type.

In addition, stimulus type (which is whether the letter is a target, a graphic variant or a different character acting as a distractor) affected letter recognition. The target letters (63\%) which have a higher frequency of occurrence were recognised with the highest percentage of accuracy and their allographs (59\%) were discriminated with a greater accuracy rate than the distractors (53.3\%), which were presented in nonsense words. This association between stimulus type and percentage of accurate recognition was so great that it could reach a level of statistical significance $\left[\mathrm{x}^{2}(2,30)=34.22, \mathrm{P}=0.05\right]$, as confirmed by the Chi-Square Test.

\section{[6] DIsCUSSION}

The main objective of this study was to assess the effects of frequency, gender and contexts on visual recognition of the four Amharic letters and their graphic variants. Specifically, the study aimed at examining the impact of the variables on reaction time and percentage of accurate recognition of the letters.

\section{[6.1] Gender difference}

A significant gender difference was found for reaction time (only in alphabetic decision task), for accuracy of response in both experiments, the female participants outperforming the male ones. In this regard, this study has replicated the findings of the previous studies which reported that females excel over males in visual word recognition, taking a shorter time and having a higher 
percentage of accurate responses (Kaushanskaya et al. 2011, Bouchière et al. 2010). The gender difference is attributed to women's reliance on long-term memory and declarative memory in retrieving the mental templates of the letters, and on women's greater attentiveness in recognition tasks (Kaushanskaya et al. 2011). In addition, in our experiments, the participants were told to respond as quickly as possible without making many errors and this might have caused females to be more sensitive to time and have a shorter reaction time, because a previous study revealed that females pay more attention to time than males do in decision-making tasks (Lizárraga, Baquedano \& Cardelle-Elawar 2007).

\section{[6.2] Frequency of occurrence and stimulus type}

Frequency of occurrence of letters was considered in the second experiment where we thought it was relevant, and the result of the experiment has indicated that no significant effect of letter frequency on reaction time was attested, although the more frequent letters were recognised faster. Lack of significant effect may be due to the fact that letter frequency effect is mediated by letter position, with the word initial letter carrying more weight in word recognition as reported by past studies (Stevens and Grainger 2003, Inhoff, Radach, Eite \& Skelly 2003, Lavidor, Hayes, Shillcock, \& Ellis 2004, Grainger, Tydgat \& Issele 2010). No provision was made for such a mediating factor in our computation of letter frequency (Chetail 2015). However, consistent with previous studies (Bouchière et al. 2010) and our intuition, letters which are more frequent had a higher percentage of accuracy.

The last interesting finding of the study is that a significant effect of stimulus type on reaction time was found in both experiments, with the targets (letters which were paired with themselves in the first experiment) taking a significantly shorter response latency and having more accurate responses than their graphic variants and distractors in nonsense words. It was also observed that the graphic variants of the four letters were recognised with shorter reaction time and a higher percentage of accurate responses. It is possible to see that orthographic inconsistency (where more than one graphic character is mapped into one phoneme) negatively affects recognition of letters in isolation and in word contexts (Grainger et al. 2003). In addition, more effects or associations of the variables (frequency, stimulus type and gender) were observed in the second experiment where the letters were presented in real words, and this replicates the finding of previous studies which reported a word superiority effect as contrasted to nonsense words (Grainger et al., 2003, Lanthier et al., 2009, Coch and Mitra 2010). 


\section{[6.3] Physical features of letters}

In the alphabetic decision task of our experiment, the participants had a shorter reaction time and a higher percentage of accurate responses when they were presented with the same letters in a pair, than when presented with graphic variants or different letters in a pair. The finding led us to the conclusion that during letter recognition, readers might have attended to their physical features, regardless of whether the letters represent the same or different phonemes. When the participants were asked to decide if a pair of letters with the same features stand for the same phoneme, their recognition rate was relatively higher, as the neural network already activated for the first character might be readily available for the second letter, so reducing the processing time, which may include the time for searching for the right mental template for the letter being recognised. Previous studies in neuroscience reported that letters with same features activate same neural networks (Petersen et al., 1990) and this can result in a shorter reaction time. It is possible that the participants could have used their background knowledge about the orthography of the language when they mapped the letters onto their phonological representations (Martin et al. 2006). They know that Amharic does not have a letter which stands for more than one phoneme, and thus when they have known that the letters in a pair are the same, their decision will be automatic.

Similarly, when a letter was presented with its graphic variants, the participants might need both orthographic and phonological information to determine whether or not the letters represent the same phoneme (McClelland \& Rumelhart 1981, Rey et al. 2000). Since the letters have different features, processing the features of each letter, mapping onto their respective orthographic representations, are necessary cognitive activities (Pušnik et al. 2016). However, knowing the orthographic representations of a letter and its graphic variants does not help the participants to automatically find their phonological representations; mapping different letters onto the same phonological representation may require more cognitive effort, resulting in a relatively longer reaction time (Flowers et al. 2004). In our experiment, this time is longer than the time needed for determining if a pair of the same letters stands for the same phoneme, which suggests that mapping letters onto different phonological representations requires more processing time or more mental effort (Sanocki \& Dyson 2012).

Priming effects could also account for the differences in recognition of Amharic letters and their graphic variants, and priming experiments on uppercase and lowercase letters are particularly very relevant (Arguin and Bub 1995, Ziegler et al. 2000). In such experiments, it was hypothesized that uppercase and 
lowercase letters (e.g., a-A) which have different shapes could produce a priming effect only in a naming task, because the task requires access to phonological representations of the letters. The hypothesis was based on the observation that the letters would share the same phonological representation, regardless of differences in physical features (Arguin and Bub 1995). However, it was not clear whether participants should have access to their phonological representations in visual alphabetic decision tasks and if the letters had the same or different abstract orthographic representations. A series of experiments conducted by (Ziegler et al.2000) confirmed that the letters can prime each other in alphabetic decision and naming tasks, regardless of their shapes. By the same token, in our experiments in alphabetic decision tasks where letters were presented with themselves ( e.g., $<h \quad h>$ ) and with their graphic variants (e.g., $<$ h $0>$ ), identity priming and cross-variant priming might have caused the difference in reaction time and accuracy of responses. In both cases, the effect is facilitatory but it is evidently higher in the identity priming.

\section{[7] CONCLUSIONS}

Gender had a significant effect on the processing time of the Amharic letters when the letters were presented in isolation, not when they were in words, with the female participants having shorter response latency. The female participants also had a significantly higher percentage of correct responses, showing a significant association between gender and accurate recognition of letters both in isolation and in words. The participants took a longer time to recognise the less frequent letters, which suggests that frequency of occurrence has an impact on recognition of letters in words, but not to the extent that its effect is significant. However, a significant association was found between a letter frequency and accurate recognition, with the more frequent letters receiving a higher percentage of correct responses. Orthographic inconsistency seems to significantly affect response latency and accurate recognition of redundant letters, as the target letters were recognised significantly faster with a higher percentage of correct responses when there is one-to-one orthographic and phonological mapping rather than when there is more than one mapping.

\section{[8] Limitations AND FUTURE RESEARCH}

We used DMDX, which is not as robust as other psycholinguistic software packages (such as E-Prime) in calculating reaction time. We believe that this limitation may have affected the results of our experiments to some extent. Future research which is more comprehensive and robust in its experimental design and use of software is needed to validate the results of our experiments. 


\section{AC KNOWLEDGMENTS}

This paper has been presented at the Rondane Workshop and published with the financial assistance of the Linguistic Capacity Building Project funded by NORHED.

\section{REFERENCES}

Adelman, James S., Suzanne J. Marquis, \& Maura G. Sabatos-DeVito. 2010. Letters in words are read simultaneously, not in left-to-right sequence. Psychological Science 21 (12). 1799-1801. http://doi.org/10.1177/0956797610387442

Appelman, Ira B. \& Mark S. Mayzner, 1981. The letter-frequency effect and the generality of familiarity effects on perception. Perception and Psychophysics 30. 436-446.

Arguin, Martin \& Daniel Bub. 1995. Priming and response selection processes in letter classification and identification tasks. Journal of Experimental Psychology-Human Perception and Performance 21. 1199-1219.

Bloor, Thomas. 1995. The Ethiopic writing system: a profile. Journal of the Simplified Spelling Society 19. 30-36.

Bouchière, B., Ponce, C. \& Foulin, J. N. 2010. Développement de la connaissance des lettres capitales. Étude transversale chez les enfants français de trois à six ans. Psychologie Francaise 552. 65-89. http://doi.org/10.1016/j.psfr.2009.12.001

Chetail, Fabienne. 2015. Reconsidering the role of orthographic redundancy in visual word recognition. Frontiers in Psychology 6. 645 http://doi.org/10.3389/fpsyg.2015.00645

Chitiri, Helena- Fivi. \& Dale M Willows. 1994. Word recognition in two languages and orthographies: English and Greek. Memory and Cognition 22 (3).313-325.

Cho, Jeug- Ryeul. \& Hsuan-Chin Chen. 1999. Orthographic and phonological activation in the semantic processing of Korean Hanja and Hangul. Language and Cognitive Processes 14. 481-502.

Coch, Donna \& Priya Mitra. 2010. Word and pseudoword superiority effects reflected in the ERP waveform. Brain Research 1329. 159-174.

Daniels, Peter T. 1999. Review of Bekerie, Ayele, Ethiopic, An African Writing System: Its History and Principles. H-Africa, H-Net Reviews. March, 1999. 
URL: http://www.h-net.org/reviews/showrev.php?id=2854

Demirel, Shaban, Roger S. Anderson, Steven C. Dakin \& Larry N. Thibos. 2012. Detection and resolution of vanishing optotype letters in central and peripheral vision. Vision Research 59. 9-16.

Derib Ado Jakale. 2011. An acoustic analysis of Amharic vowels, plosives and ejectives. PhD Thesis. Addis Ababa University.

Evans, Mary Ann, Jean Saint-Aubin \& Nadine Landry. 2009. Letter Names and Alphabet Book Reading by Senior Kindergarteners: An Eye Movement Study. Child Development 806. 1824-1841.

Fiset, Daniel, Caroline Blais, Catherine Éthier-Majcher, Martin Arguin, Daniel Bub \& Frédéric Gosselin. 2008. Features for identification of uppercase and lowercase letters. Psychological Science 19(11). 1161-1168.

Fiset, Daniel, Caroline Blais, Catherine Éthier-Majcher, Martin Arguin, Daniel Bub \& Frédéric Gosselin. 2004. Attention to single letters activates left extrastriate cortex. $\quad$ Neuroimage 21(3). http://doi.org/10.1016/j.neuroimage.2003.10.002

Flowers, Donna, K. Jones, Kimberly G. Noble, J. Vanmeter, F. B. Wood \& Guinevere F Eden. 2004. Attention to single letters activates left extrastriate cortex. Neuroimage 21(3). 829-839.

Forster, Kenneth \& Jonathan C. Forster. 2003. DMDX: A windows display program with millisecond accuracy. Behavioural Research Methods, Instruments, and Computers. 35.116-124.

Frost, Ram. 2005. Orthographic Systems and skilled word recognition processes in reading. In M. J. Snowling and C. Hulme (Eds). The Science of Reading: A Handbook pp. 272-295. Oxford: Blackwell.

Gibson, J. Eleanor. 1969. Principles of perceptual learning and development. New York: Appleton-Century-Crofts.

Grainger, Jonathan, Sebastien Bouttevin, Cathy Truc, Mireille Bastien, \& Johannes Ziegler. 2003. Word superiority, pseudoword superiority, and learning to read: a comparison of dyslexic and normal readers. Brain and Language, 873, 432-440. http://doi.org/10.1016/S0093-934X0300145-7 
Grainger, Jonathan, Ilse Tydgat \& Joanna Issele. 2010. Crowding affects letters and symbols differently. Journal of Experimental Psychology: Human Perception and Performance 36(3). 673-688. http://doi.org/10.1037/a0016888.

Huang, H S \& J Richards Hanley. 1994. Phonological awareness and visual skills in learning to read Chinese and English. Cognition 54 (1). 73-98.

Hubel, H. David \& Wiesel Torsten N. 1968. Receptive fields and functional architecture of monkey striate cortex. Journal of Physiology, 195(1). 215-243.

Inhoff, Albrecht W, Ralph Radach, Brianna M Eiter \& Michael Skelly. 2003. Exterior letters are not privileged in the early stage of visual word recognition during reading: comment on Jordan, Thomas, Patching and Scott-Brown (2003). Journal of Experimental Psychology: Learning, Memory, and Cognition 29(5). 894-899.

James, Karin H., Thomas W. James, Gael Jobard, Alan C.N. Wong \& Isabel Gauthier 2005. Letter processing in the visual system: different activation patterns for single letters and strings. Cognitive, Affective and Behavioral Neuroscience 5(4). 452-466. http://doi.org/10.3758/CABN.5.4.452

Ju, Daushen, \& Nancy Ewald Jackson. 1995. Graphic and phonological processing in Chinese character identification. Journal of Reading Behavior 27 (3). 299-313. http://doi.org/10.1080/10862969509547885

Kashino, Makio. 2006. Phonemic restoration: the brain creates missing speech sounds. Acoustical Science and Technology 27 (6). 318-321. http://doi.org/10.1250/ast.27.318.

Kaushanskaya, Margarita, Viorica Marian \& Jeewon Yoo. 2011. Gender differences in adult word learning. Acta Psychologica. 137(1). 24-35. http://doi.org/10.1016/j.actpsy.2011.02.002

Kwon, MiYong \& Gordon E Legge.2013. Higher-contrast requirements for recognizing low-pass - filtered letters. Journal of Vision 13, 1-15. http://doi.org/10.1167/13.1.13.Introduction

Lanthier, Sophie N, Evan F Risko, Jennifer Stolz \& Derek Besner. 2009. Not all visual features are created equal: early processing in letter and word recognition. Psychonomic Bulletin and Review 16 (1). 67-73. http://doi.org/10.3758/PBR.16.1.67.

Lavidor, Michal, Adrian Hayes, Richard Shillcock, \& Andrew W Ellis. 2004. Evaluating a split processing model of visual word recognition: Effects of ortho- 
graphic neighborhood size. Brain and Language 88 (3). 312-320. http://doi.org/10.1016/S0093-934X0300164-0

Lesch, Mary F. \& Alexander Pollatsek. 1993. Automatic access of semantic information by phonological codes in visual word recognition. Journal of Experimental Psychology: Learning, Memory, and Cognition 19 (2). 285-294.

Leslau, Wolf. 2000. Introductory Grammar of Amharic. Wiesbaden: Harrassowitz Verlag.

Lizárraga, María L. Sanz de Acedo, María T. Sanz de Acedo Baquedano \& y María Cardelle-Elawar. 2007. Factors that affect decision making: gender and age differences. International Journal of Psychology and Psychological Therapy 7(3). 381-391.

Lukatela, Georgije \& M.T. Turvey. 1994. Visual lexical access is initially phonological: 1. Evidence from associative priming by words, homophones, and pseudo homophones. Journal of Experimental Psychology. General 123 (2). 107128.

Martelli, Marialuisa, Najib J. Majaj \& Denis G. 2005. Are faces processed like words? A diagnostic test for recognition by parts. Journal of Vision 5 (1). 6 , 58-70.

Martin, Clara D., Tatjana Nazir, Guillaume Thierry, Yves Paulignan \& Jeanfrançois Démonet. 2006. Perceptual and lexical effects in letter identification: an event-related potential study of the word superiority effect. Brain Research 1098 (1).153-160. http://doi.org/10.1016/j.brainres.2006.04.097

McBride-Chang, Catherine \& Rebecca Treiman. 2003. Hong Kong Chinese kindergartners learn to read English analytically. Psychological Science 14(2). 138-143.

McClelland, James L. \& David E. Rumelhart. 1981. An interactive activation model of context effects in letter perception: Part 1 An account of basic findings. Psychological Review 88 (5). 375-407.

Pelli, Denis G., Bart Farell \& Deborah C. Moore. 2003. The remarkable inefficiency of word recognition. Nature 423. 752-756.

Pelli, Denis. G., Melanie Palomares \& Najib J. Majaj. 2004. Crowding is unlike ordinary masking: Distinguishing feature integration from detection. Journal of Vision 4(12). 1136-1169. 
Petersen, Steven E., Peter T. Fox, Abraham Z. Snyder, \& Marcus E. Raichle. 1990. Activation of extrastriate and frontal cortical areas by visual words and word-like stimuli. Science 249(4972). 1041-1044.

Pugh, Keneth R., W. Einar Mencl , Annette R. Jenner, Leonard Katz, Stephen J. Frost, Jun Ren Lee, Sally E. Shaywitz \& Benett A. Shaywitz. 2001. Neurobiological studies of reading and reading disability. Journal of Communication Disorders 34(6). 479-492.

Pušnik, Nace, Klementina Možina, \& Anja Podlesek. 2016. Effect of typeface, letter case and position on recognition of short words presented on-screen. Behaviour and Information Technology 35(6). 442-451. http://doi.org/10.1080/0144929X.2016.1158318.

Ranbom, Larissa J. \& Cynthia M. Connine. 2011. Silent letters are activated in spoken word recognition. Language and Cognitive Processes 26(2). 236-261. http://doi.org/10.1080/01690965.2010.486578

Rayner, Keith \& Rebecca L. Johnson. 2005. Letter-by-letter acquired dyslexia is due to the serial encoding of letters. Psychological Science 16(7). 530-534.

Rey, Arnaud \& Niels O. Schiller. 2005. Graphemic complexity and multiple print-to-sound associations in visual word recognition. Memory and Cognition 33(1). 76-85.

Rey, Arnaud, Johannes C Ziegler \& Arthur M Jacobs. 2000. Graphemes are perceptual reading units. Cognition 75(1). B1-12.

Sanocki, Thomas. 1992. Effects of font- and letter-specific experience on the perceptual processing of letters. The American Journal of Psychology 105(3). 435-458.

Sanocki, Thomas \& Mary C. Dyson. 2012. Letter processing and font information during reading: Beyond distinctiveness, where vision meets design. Attention, Perception and Psychophysics 74(1). 132-145. http://doi.org/10.3758/s13414-011-0220-9

Share, David L \& Talya Gur. 1999. How reading begins: a study of preschoolers' print identification strategies. Cognition and Instruction 17 (2) 177-213.

Stevens, Michael \& Jonathan Grainger. 2003. Letter visibility and the viewing position effect in visual word recognition. Perception and Psychophysics 65(1). 133-151. http://doi.org/10.3758/BF03194790 
Yamashita, Junko. 2013. Word recognition subcomponents and passage level reading in a foreign language. Reading in a Foreign Language 25(1). 52-71.

Moges Yigezu. 2010. Language Ideologies and Challenges of Multilingual Education in Ethiopia: the Case of Harari Region. Addis Ababa: Organization for Social Science Research in Eastern and Southern Africa OSSREA.

Ziegler, Johannes C., Ludovic Ferrand, Arthur M. Jacobs, Arnaud Rey \& Jonathan Grainger. 2000. Visual and phonological codes in letter and word recognition: evidence from incremental priming. The Quarterly Journal of Experimental Psychology Section A 53(3). 671-692. http://dx.doi.org/10.1080/713755906

Ziegler, Johannes C., Ludovic Ferrand \& Marie Montant. 2004. Visual phonology: The effects of orthographic consistency on different auditory word recognition tasks. Memory and Cognition 32 (5). 732-741.

\section{CONTACTS}

Feda Negesse

Department of Linguistics and Philology

Addis Ababa University

Ethiopia

feda.negesse@aau.edu.et/ fedan2010@gmail.com

Derib Ado

Department of Linguistics and Philology

Addis Ababa University

Ethiopia

derib.ado@aau.edu.et 
